\section{Exciting charity news to share with delegates}

The British Dental Conference and Dentistry Show Birmingham 2022 will be supported by an array of professional organisations, associations and charities. Among them will be Dentaid, with the team keen to meet new people and share their latest news.

Andy Evans, Dentaid CEO, commented:

'We're so excited to be returning to the British Dental Conference and Dentistry Show Birmingham. As a charity that relies on the generosity of our supporters and volunteers, it's so important for us to meet people in the dental industry and tell them how our projects change people's lives. We've got so much exciting news new mobile dental units, additional clinics for homeless and vulnerable people across the UK, the restart of our overseas volunteering programme - so it will be a great opportunity for us to let people know how they can volunteer their time and get involved.

'In the last two years, demand for our charitable services has skyrocketed and we're helping more people than ever before. Our mobile dental units travel from Weymouth to York and Exeter to Norfolk helping the most vulnerable people in our communities to access dental care.

'We're also excited to be inviting people to sign up for our overseas volunteering programmes as our support for our dental partners overseas is more important than ever. There's always something going on at Dentaid and the British Dental Conference and Dentistry Show Birmingham will be the perfect opportunity for us to tell the dental profession about it.'

The next British Dental Conference and Dentistry Show Birmingham will be held on Friday 13 and Saturday 14 May 2022, Birmingham NEC, co-located with DTS.

For more information, visit https:// birmingham.dentistryshow.co.uk/, or email dentistry@closerstillmedia.com.

\title{
Successfully delivering more comfortable injections
}

CALAJECT, a device for computerassisted local anaesthesia, has received the esteemed recognition '2022 Top Award Winner - Anesthetic Device' by Dental Advisor.

CALAJECT was evaluated by six consultants and used 153 times in total and the highlighted features were: ergonomic unit with small footprint, good visual displays and auditory signal, controls flow of local anaesthetic and automated aspiration.

CALAJECT was designed to deliver more comfortable injections. The system controls the flow rate, which ensures a smooth and gentle flow of anaesthesia. Even palatal injections can be carried out with less discomfort for the patient. Once anxious patients have learned that dental shots don't hurt, they tend to relax and become confident, which is advantageous for both patient and dentist.

The secret is an intelligent and gentle administration of the anaesthetic solution which prevents the pain that typically

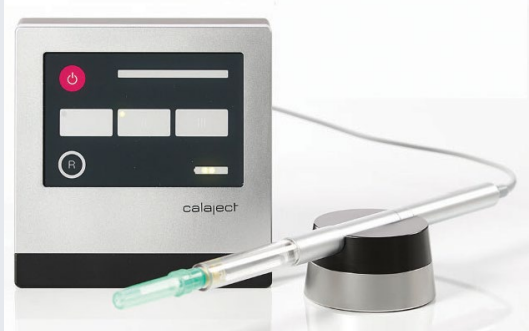

occurs when an injection is given too quickly. CALAJECT features three program settings which are carefully designed for the most common local anaesthesia techniques used in the oral cavity: intraligamental and palatal injections, infiltrations and nerve block anaesthesia.

The pen-grip allows the operator to sit in a relaxed and ergonomic position while injecting. No finger power is needed and any strain on muscles and joints is avoided. In addition, the possibility of obtaining a good finger support allows you to hold the needle perfectly still during injection, which gives a good control of the position of the needle tip. Combined with the automatic aspiration feature, safe injections are made easier to perform.

RØNVIG Dental Mfg. A/S has produced and marketed the well-known 'Dr. Evers' ASPIJECT and PAROJECT injection syringes for more than 25 years. CALAJECT is the company's second generation of computer-assisted injection system. It is produced to the highest of precision and electronic engineering standards. The ambition is to provide even better local analgesia in dentistry - with minimum pain and discomfort for the patient and with improved ergonomic features for benefit of the dentist.

RØNVIG is a proud member of the Directa Dental Group. Learn more about CALAJECT and the other RØNVIG products at www.ronvig.com.

\section{Everything you need to start simple implant treatments}

Supported by Trycare and Adin implants, the Quest Implantology Course 2022 teaches delegates everything they need to start implementing simple implant treatment plans, plus 36 hours of CPD.

Royal College of Surgeons of Edinburgh accredited and presented by Girish Bharadwaj, the course gives delegates a thorough basic knowledge of implantology, including an overall perspective with an evidence-based approach; necessary surgical and restorative skills to implement simple treatment plans; an understanding of the challenges involved in the surgical and prosthetic phases of treatment; and an understanding of when to refer based upon skill levels.

Completion of the course will enable participants to diagnose and carry out implant treatment planning; carry out initial risk assessment and consent the patient appropriately; insert and restore implants under supervision in a simulated environment; identify the complexity of individual cases and place implants in simple cases under supervision; and know when to refer for additional support and guidance.

Held in Edinburgh, course fees are $£ 1,250.00$ (including vat) per module and $\mathfrak{1} 3,500.00$ (including vat) for the full course.

For further information or to book your place contact info@ochilviewdental.co.uk. 